\title{
SAÚDE AMBIENTAL E PROMOÇÃO DA SAÚDE: EXPERIÊNCIA DE ENSINO NA ENFERMAGEM
}

\section{ENVIRONMENTAL HEALTH AND HEALTH PROMOTION: EXPERIENCE IN NURSING EDUCATION}

\author{
Francisco Gilberto Fernandes Pereira ${ }^{1}$, Márcia Barroso Camilo de Ataíde $^{2}$ e Joselany \\ Áfio Caetano ${ }^{3}$ \\ ${ }^{1}$ Docente do Curso de Enfermagem da Faculdade Estácio-FIC, Ceará. \\ ${ }^{2}$ Docente do Curso de Enfermagem da Universidade de Fortaleza. \\ ${ }^{3}$ Docente do Curso de Enfermagem da Universidade Federal do Ceará.
}

\begin{abstract}
RESUMO
Objetivou-se descrever a experiência vivenciada por alunos de um curso técnico de enfermagem durante as aulas de educação para o autocuidado com enfoque para a promoção da saúde. Trata-se de um relato de experiência sobre atividade educativa realizada com 120 estudantes de técnico de enfermagem, entre fevereiro e março de 2012. Utilizaram-se aulas expositivas e produção de materiais audiovisuais a partir de atividades extramuros nas comunidades de Fortaleza. A verificação da aprendizagem operacionalizou-se pela avaliação de conteúdo. Os resultados reforçam a necessidade de discussão da saúde ambiental nos espaços de formação, evidenciando a promoção da saúde como marco conceitual apropriado para estabelecer a relação homem e ambiente. A participação ativa do discente na atividade de campo foi momento singular na concretização do aprendizado, solidificação do conhecimento, e mobilização do trabalho em equipe. Sugere-se que outras metodologias possam ser empregadas, e que a saúde ambiental possa ser conteúdo transversal na formação profissional.
\end{abstract}

Palavras-chave: educação; estudantes de enfermagem; promoção da saúde; saúde ambiental.

\begin{abstract}
The objective was to describe an experience for students of a nursing technical course during school environmental education with a focus on health promotion. This is an experience report on educational activities carried out with 120 students of nursing technicians, between February and March 2012. We used lectures and production of audiovisual materials from extramural activities in the communities of Fortaleza. Verification of the learning by the evaluation operationalized content. The results reinforce the need for discussion of environmental health in areas of training, emphasizing health promotion as a conceptual framework appropriate to establish the link man and environment. The active participation of students in the field activity was singular moment in the realization of learning, solidification of knowledge, and mobilization of teamwork. It is suggested that other methodologies may be employed, and that environmental health can be content in cross training.
\end{abstract}

Key words: Education; Nursing students; Health promotion; Environmental health. 


\section{Introdução}

Há um consistente entrelaçamento no século XXI entre os pilares da educação, saúde e ambiente. Esta constatação é possível devido às relações estabelecidas entre o intenso avanço tecnológico associado à globalização, fruto de uma política capitalista que prioriza a lucratividade em detrimento das relações harmônicas entre homem e ambiente.

Nesta perspectiva algumas possíveis soluções têm sido propostas, entre elas a Promoção da Saúde: um novo estilo de vida pautado entre outros aspectos numa relação mais simbiótica entre o homem e o ambiente em que vive, de forma que possa existir desenvolvimento sem que a saúde e seus determinantes sejam negativamente afetados. E, sua metodologia de execução envolve os cenários: político, educacional e assistencial (BESERRA, et al, 2010).

Mas, será que os cursos da área de saúde, superior e técnico, têm introduzido em suas propostas metodológicas e diretrizes educacionais formadoras a temática da saúde ambiental como relevante nos pressupostos da Promoção da Saúde? Aproximando-se a essa indagação, percebe-se na literatura que a enfermagem é uma das profissões que mais tem se inteirado dessa discussão numa postura densa por meio das ações de educação em saúde (SILVA, et al, 2009).

Os projetos pedagógicos dos cursos técnicos em enfermagem ainda têm trabalhado de forma tímida a saúde ambiental (BRASIL, 2000). No entanto, há disciplinas teóricas em que essa abordagem é possível como no caso de biossegurança, saúde coletiva e educação para o autocuidado.

Ao perceber que as aulas convencionais destas disciplinas em um curso técnico de enfermagem necessitavam de reformulação para se adequar às discussões mais atuais, foi emergente a criação de uma metodologia que permitisse aos discentes a oportunidade de compreender de modo prático as implicações que o ambiente pode determinar na saúde das pessoas. E a experiência extramuros foi vista então como ferramenta possível por ser de baixo custo e facilmente exequível, além de aproximar o sujeito da realidade.

Fundamentado nas diretrizes da participação comunitária e do controle social, assim como no entendimento que a promoção da saúde está caracterizada em um de seus eixos pelas questões ambientais, faz-se oportuno problematizar e enriquecer a discussão sobre a temática na sala de aula, para que desta forma haja sensibilização do 
discente na compreensão da saúde como um conceito mais amplo e do qual é protagonista.

Deste modo o objetivo do estudo é descrever a experiência vivenciada por alunos de um curso técnico de enfermagem durante as aulas de educação para o autocuidado com enfoque para a promoção da saúde.

\section{Metodologia}

Trata-se de um relato de experiência acerca das habilidades desenvolvidas e conhecimentos adquiridos por alunos de um curso técnico de enfermagem durante as aulas de educação ambiental, em que se buscou estabelecer relações diretas com a promoção da saúde.

O grupo participante do estudo foi composto por 120 alunos de um curso técnico de enfermagem sediado na cidade de Fortaleza-Ceará.

As atividades ocorreram nos meses de fevereiro e março de 2012 durante o curso da disciplina educação para o autocuidado, a qual se desmembra nos seguintes módulos de aprendizagem: higiene e profilaxia (educação ambiental), biossegurança e nutrição e dietética. Tem como ementa principal a problematização das questões ambientais e o impacto que estas causam na saúde humana, bem como os meios para se criar ambientes saudáveis, com enfoque no saneamento básico.

Os encontros foram realizados durante um período de 15 dias em sala de aula e divididos em duas partes, sendo o primeiro um módulo teórico, em que foram discutidos os conceitos de saúde ambiental, saneamento básico e seus componentes (água, resíduos sólidos e esgoto), males gerados pela escassez de ambiente saneado, responsabilidade civil e pública pela preservação da saúde ambiental, promoção da saúde e métodos de controle social para o bem-estar do meio ambiente.

Enquanto o segundo reservou-se para a construção de materiais audiovisuais (fotos, vídeos) pelos discentes relacionados á temática, em caráter extramuros nos bairros de Fortaleza-Ceará e com orientação do professor. Este momento também foi oportuno para se completar a avaliação da aprendizagem adquirida durante as aulas teóricas, sendo considerado pelo professor (moderador) como aprendizado satisfatório quando o aluno conseguisse estabelecer por meio de seu constructo as relações entre saúde ambiental e promoção da saúde.

O modelo utilizado foi o de avaliação de conteúdo, que tem como propósito determinar se os aprendizes adquiriram o conhecimento ensinado durante a experiência 
de aprendizagem. Sua abrangência é limitada a uma experiência de aprendizagem específica e aos objetivos estabelecidos para essa experiência. Ela ocorre em um ponto circunscrito no tempo, logo após a conclusão do ensino, mas abrange todas as atividades de ensino-aprendizagem incluídas na atividade, e, os dados são obtidos de todos os aprendizes da turma. Na perspectiva da avaliação de conteúdo a demonstração da evidência interna determina se os objetivos de certo grupo de aprendizes foram alcançados (BASTABLE, 2010).

\section{Bases convergentes entre Saúde Ambiental e Promoção da Saúde para a construção do material teórico}

Saúde ambiental é um tema atual que pode ser conceituado como um conjunto de atitudes, pensamentos e ações direcionados para a preservação do meio ambiente por meio de uma relação sustentável com o homem, contribuindo para uma compreensão maior sobre a complexidade em que está envolvido o ambiente, além de se configurar como um dos pilares da responsabilidade socioambiental vigente (MARCHIORATOCARNEIRO, 2006).

A pauta ambiental aparece notoriamente nos documentos que orientam a Promoção da Saúde, mais especificamente na Carta de Otawa, onde são sugeridas condições mínimas para a saúde, entre elas a sustentabilidade do ecossistema, e a criação de ambientes favoráveis à saúde (BRASIL, 2001).

A relação entre a questão ambiental e o movimento da promoção da saúde, tem proporcionado a introdução de novas abordagens no campo da saúde pública e da educação com vistas a reunir abordagens sistêmicas e sociais no entendimento do homem como ser ativo na adaptação do meio ambiente no favorecimento da sua saúde e do planeta. A atual conformação desse novo paradigma é fruto do espaço que a promoção da saúde tem conquistado na elaboração das políticas públicas (PORTO, MARTINEZ-ALIER, 2007).

Nesse contexto, a enfermagem como ciência do cuidado, é desafiada a reorientar caminhos que fortaleçam essa discussão e gere respostas de forma crítica e reflexiva às questões postas como relevantes na sociedade atual. De modo que, a capacidade para agir de forma transformadora nos espaços favoráveis à saúde perpasse pela responsabilidade ecológico-ambiental que necessita ser abordada durante o processo de formação profissional (SILVA, 2008). 
Em um documento do Ministério da Educação (MEC) que orienta os Referenciais Curriculares Nacionais para Educação Profissional de Nível Técnico (BRASIL, 2000) está evidente que uma das competências a serem desenvolvidas nesses futuros profissionais é a capacidade de compreender a relação entre o meio ambiente e a saúde das pessoas, enfatizando que devem ser encorajados meios possíveis de intervenção, bem como participação de maneira proativa na localização e reconhecimento de áreas/ambientes que ofereçam risco à saúde na comunidade.

A partir deste entendimento, os idealizadores desta experiência revisaram os conteúdos programáticos de todas as disciplinas teóricas de um curso técnico de enfermagem buscando um espaço que proporcionasse o enriquecimento da discussão entre as duas temáticas em destaque: saúde ambiental e promoção da saúde. E foram sugeridas as disciplinas de saúde coletiva, educação para o autocuidado e biossegurança, por apresentarem conteúdos convergentes com o assunto proposto.

Educação para o autocuidado foi selecionada por ter carga horária suficiente, e por ser a que apresenta na sua programação de conteúdo ementas relativa ao saneamento básico, conceito de meio-ambiente, processo saúde-doença e responsabilidade ambiental. Posteriormente, esses assuntos foram revisados pelos professores e incrementados aqueles que estavam ausentes ou desatualizados.

Os recursos utilizados foram: construção de uma apostilha com discussão teórica aprofundada, com exercícios de revisão, quadros de resumo e sessões de aplicação prática com enfoque na temática abordada; e, aulas expositivas com suporte de mídia digital elaborada no Power-point.

As aulas foram ministradas aos discentes regularmente matriculados no curso, e aconteceram por dez dias durante o período noturno com duração de três horas para cada encontro. Os temas conferenciados foram: conceito de saúde, promoção da saúde e prevenção de doenças, saúde ambiental, higiene e autocuidado, profilaxia, saneamento básico, classificação e destino dos resíduos sólidos dos serviços de saúde, e, relação entre infecção e meio-ambiente.

\section{Vivência prática e avaliação de conteúdo}

Complementarmente às atividades teóricas, surgiu a necessidade de tornar os conceitos apreendidos mais próximos da realidade dos discentes por meio de vivência prática, suscitando assim a ideia de um construto audiovisual elaborado pelos alunos 
que apresentasse os ambientes que se enquadrassem em positivos e negativos para a saúde, conforme o que haviam aprendido, nas diversas localidades de Fortaleza.

A sugestão para a elaboração dos materiais audiovisuais se apoiou na hipótese de que este tipo de recurso enriquece o processo educativo estimulando os sentidos visual e auditivo, acrescentando variedade à experiência de ensino-aprendizagem e gerando memórias visuais. Além disso, incrementam a retenção da informação por meio do que se vê e se ouve, influenciando de maneira positiva na promoção do domínio cognitivo, no estímulo à mudanças de atitudes e construção de habilidades psicomotoras (BASTABLE, 2010).

O constructo audiovisual se encaixou bem como material de demonstração de aprendizagem, por reunir as seguintes vantagens: ferramenta amplamente usada, de baixo custo, usa duplamente os sentidos da visão e audição e é flexível para diversos públicos. Foi oferecido apoio com aparelhos digitais de captura de imagens como máquina fotográfica e filmadora para os discentes que não as possuíam, como forma de sanar possíveis entraves que ocorressem para a execução da atividade.

A turma foi então dividida em grupos de composição numérica variada, sendo o menor grupo de três e o maior de dez alunos, com um aspecto em comum que era o de residirem no mesmo bairro ou comunidade onde desejassem realizar a aplicação prática complementar da atividade. Ao todo foram compostas 20 equipes que visitaram os seguintes bairros: Fátima, Aldeota, Meireles, Bom Jardim, Pirambu, Conjunto Esperança, Aerolândia, Messejana, Conjunto José Walter, Praia do Futuro, Praia de Iracema, Maraponga, Benfica, Centro, Lagoa Redonda, Água Fria, Parangaba, Alagadiço, Quintino Cunha e Antônio Bezerra.

As respectivas localidades citadas compõem um panorama misto representativo da cidade de Fortaleza, uma vez que pertencem a Secretarias Executivas Regionais (SER) distintas, com realidades socioeconômicas, educacionais e de infraestrutura divergentes. Este fato tornou a experiência mais ilustrativa e permitiu que o grupo visualizasse outras realidades diferentes tornando a comparação inevitável.

Os cenários registrados na experiência extramuros foram divididos para apresentação do material audiovisual (fotos e vídeos) em pontos positivos e negativos do meio ambiente em relação à promoção da saúde, onde podem ser verificadas no quadro que se segue as principais características observadas pelos alunos: 


\section{PONTOS POSITIVOS}

- Sistema de tratamento e abastecimento de água;

- Postos de coleta seletiva de lixo em alguns estabelecimentos comerciais;

- Ciclovias;

- Coleta de lixo doméstico sólido em dias alternados na maioria dos bairros;

- Fábricas de reciclagem;

- Lagoas urbanas;

- Parques ecológicos.

\section{PONTOS NEGATIVOS}

- Lixo a céu aberto;

- Drenagem ineficiente de esgoto;

- Focos de dispersão de resíduos de serviços de saúde em vias públicas;

- Recicladores informais manipulando o lixo sem Equipamentos de Proteção Individual;

- Terrenos baldios com acúmulo de pneus e garrafas;

- Rios e córregos poluídos por ação de esgotos e acessíveis à população.

Quadro 1: Características positivas e negativas do meio-ambiente em relação à Promoção da Saúde registrados por alunos durante atividade extramuros em FortalezaCeará.

À medida que as apresentações aconteceram, foi citado espontaneamente pelos alunos que algumas medidas foram tomadas por eles próprios junto aos órgãos governamentais competentes para resolução imediata ou sensibilização para o problema detectado. Essa consequência tornou-se inevitável, pois quando se sensibiliza um grupo sobre educação e saúde ambiental, este se sente impelido a influenciar nas decisões sócio-político-ambientais do meio em que atuam e no contexto onde estão inseridos com sensibilidade apurada para compreender a relação homem, saúde e ambiente (CAMPONOGARA, VIERO, SARI, ERTHAL, 2011).

Algumas dificuldades foram relatadas durante a atividade extramuros, por exemplo: dificuldade de acesso a determinados pontos devido ao alto índice de criminalidade e o manejo com o computador na elaboração do recurso audiovisual.

Finalmente, processou-se a avaliação da aprendizagem com um conceito satisfatório, pois a ideia central de relacionar saúde ambiental e promoção da saúde obteve sucesso.

\section{Considerações Finais}

Pode-se dizer que a vivência extramuros nos bairros de Fortaleza se configurou em uma robusta oportunidade de estabelecer a relevância da discussão da saúde ambiental no contexto da promoção da saúde humana, evidenciado pela riqueza dos materiais construídos e clareza nos discursos apresentados pelos discentes. 
Igualmente, é categórico afirmar que a fase teórica da atividade educativa propiciou a construção de alicerces críticos e reflexivos para o estabelecimento das relações convergentes entre o papel do profissional de saúde na promoção de ambientes favoráveis à saúde humana, bem como as estratégias que este pode utilizar para adaptar as melhores condições ambientais em favor do bem-estar das pessoas, numa relação simbiótica.

Portanto, sugere-se que outras metodologias sejam empregadas com essa finalidade, e que a saúde ambiental possa ser conteúdo transversal na formação profissional, uma vez que o estudo ora desenvolvido tem como premissa despertar a comunidade docente na área da saúde para discussões mais aprofundadas sobre a temática e servir como exemplo de experiência bem sucedida no campo da educação ambiental.

\section{Referências}

BASTABLE, S.B. O enfermeiro como educador: princípios de ensinoaprendizagem para a prática de enfermagem. $3^{\text {a }}$ ed. Porto Alegre: Artmed. 2010.

BESERRA, E.P.; ALVES, M.D.S.; PINHEIRO, P.N.C.; VIEIRA, N.F.C. Educação ambiental e enfermagem: uma integração necessária. Revista Brasileira de Enfermagem. v.63, n.5, p.848-852, set-out, 2010.

BRASIL, Ministério da Educação. Educação profissional: referenciais curriculares nacionais da educação profisssional de nível técnico. Área profissional: Saúde. Brasília: Ministério da Educação; 2000.

BRASIL, Ministério da Saúde. Promoção da saúde: carta de Otawa. Declaração de Adelaide Sunsvall e Santa de Bogotá. Brasília: Ministério da Saúde; 2001.

CAMPONOGARA, S.; VIERO, C.M.; SARI, V.; ERTHAL, G. A abordagem da interface saúde e meio ambiente na formação profissional de enfermeiros. Revista Gaúcha de Enfermagem. v.32, n.4, p.647-653, Dez, 2011.

MARCHIORATO-CARNEIRO, S.M. Fundamentos epistemo-metodológicos da educação ambiental. Educar. v.27, n.1, p.17-35, 2006.

PORTO, M.F.; MARTINEZ-ALIER, J. Ecologia política, economia ecológica e saúde coletiva: interfaces para a sustentabilidade do desenvolvimento e para a promoção da saúde. Cadernos de Saúde Pública. v.23, n. Sup.4, p.5503-5512, 2007.

SILVA, A.L. A enfermagem na era da globalização: desafios para o século XXI. Rev. Latino Americana de Enfermagem. v.16, n.4, jul-ago, 2008.

SILVA, K.L.; SENA, R.R.; GRILLO, M.J.C.; HORTA, N.C.; PRADO, P.M.C. Educação em enfermagem e os desafios para a promoção de saúde. Revista Brasileira de Enfermagem. v.62, n.1, p. 86-91, 2009. 